\title{
Fuel selection, muscle fibre
}

\author{
BY ERIC HULTMAN \\ Division of Clinical Chemistry, Department of Medical Laboratory Sciences and Technology, \\ Huddinge University Hospital, Karolinska Institute, S-141 86 Huddinge, Sweden
}

\section{Fibres musculaires}

\section{RÉSUMÉ}

La sélection des substrats énergétiques par les fibres musculaires dépend de l'intensité de l'exercice, du type de recrutement des fibres musculaires et de la disponibilité des substrats. Lorsque le muscle est au repos, le jeûne glucidique augmente la concentration musculaire de citrate et de groupes acétyles liés à la coenzyme $\mathrm{A}(\mathrm{CoA})$ et à la carnitine L'augmentation des rapports de concentration acétyl $\mathrm{CoA}: \mathrm{CoASH}$ inhibe la déphosphorylation de la pyruvate déshydrogénase $(\mathrm{PDH})$ vers une forme active ( $\mathrm{PDHa})$, et donc l'oxydation des glucides. Ces résultats sont en accord avec des études antérieures par Garland et al. (1963) et Garland \& Randle (1964). Au cours de l'exercice à intensité maximum, les principaux substrats sont la phosphocréatine $(\mathrm{PCr})$ et le glycogène musculaire avec la production d'énergie la plus importante en fibres de type II. La vitesse de dégradation de la $\mathrm{PCr}$ ainsi que la glycogénolyse sont à plus de $50 \%$ plus élevées dans les fibres de type II que dans celles de type I. Au cours de l'exercice à des intensités situées entre 75 et $100 \%$ de la $V_{\mathrm{O}_{2}}$ maximale, les deux types de fibres sont mobilisés, et la sélection de substrats est influencée par la disponibilité des substrats. Ainsi, quand l'ingestion d'un régime mixte normal ou riche en glucides précédait l'exercice, les réserves corporelles en glucides étaient les principales sources d'énergie fournissant à peu près $100 \%$ de l'apport total en énergie. Le complexe PDH était transformé complètement en PDHa et montrait une pleine activité catalytique malgré un rapport élevé des concentrations d'acétyl $\mathrm{CoA}: \mathrm{CoASH}$. Lorsque le régime a été changé pour une ingestion pauvre en glucides, le même exercice avec la même intensité de travail et la même durée pouvait être accompli avec jusqu'à $70 \%$ de l'énergie consistant en lipides. Le complexe PDH n'était que partiellement activé et le rapport de concentration acétyl-CoA:CoASH était faible. Il semble que les fibres de type I particulièrement ont une capacité élevée d'utiliser les lipides comme substrats énergétiques à des intensités d'exercice élevées. Dans l'exercice avec des intensités inférieures à $60 \%$ de la $V_{\mathrm{O}_{2}}$ maximale, les fibres de type I sont activées de façon préférentielle, avec une prédominance pour l'utilisation oxydative des lipides et des graisses.

A characteristic of skeletal muscle is its diversity, since it consists of various kinds of fibre which, moreover, vary within themselves. This is necessary if the muscles are to meet the daily demands of a broad range of contractile activities. The functions of the muscle in the performance of various motor tasks depend on the control of contraction by the 
central nervous system and on the intrinsic differences in the contractile spectrum among the fibres in the muscle. Activation of the appropriate muscle fibres with the appropriat $e$ patterns of neural input leads to the desired movement during contraction. ATP is utilized initially as the energy source and it must be resynthesized at the same rate as it is utilized. This means that a fine adjustment must be made between the metabolic capacity and the contraction characteristics and recruitment pattern of each type of fibre. There is also a pronounced adaptability of the metabolic capacity to the functional demands of the different fibres that can be utilized by physical conditioning. This point will be discussed by Dr Jan Henriksson (1995).

The first observation on differences in muscle fibres, was made as early as 1873 , when Ranvier described white and red muscles. The obvious difference was the high myoglobin content and the high capillarization in the red muscle, as compared with white muscle, which has a low content of both. During the last 100 years, muscle fibre types have been extensively studied both on the cellular and the molecular level (for reviews, see Armstrong, 1988; Pette \& Staron, 1990). In the present paper, the two fibre types will be denoted type I and type IIA and B. Type I is also known as slow-twitch red fibre or slow-twitch fatigue-resistant. Physiological measurements show a long twitch contraction time (time to peak tension), a relatively low maximum tetanic tension and a high fatigue resistance, i.e. a high fatigue index. Type II fibres show a short twitch contraction time, a higher maximum tetanic tension and a low fatigue index.

However, all these functions have a large spread within each fibre group. The metabolic pattern of the fibres also varies; type I showing a low ATPase (EC 3.6.1.32) activity, low creatine kinase ( $E C$ 2.7.3.2), low activity of glycolytic enzymes, but a high oxidative capacity due to high mitochondrial density, high myoglobin and a high capillary density. The metabolic pattern is adjusted to the long twitch contraction time and low force production, but it also makes the fibre fatigue-resistant by its high capacity for oxidative ATP resynthesis.

Type II fibres can be divided into two groups, IIA which has a relatively high oxidative capacity and, similar to IIB, a high myosin ATPase activity, high creatine kinase and high capacity for anaerobic glycolysis. Because of the difference in oxidative capacity, which is low in type IIB, subfraction IIB has a lower fatigue resistance than subfraction IIA (see Fig. 1; Burke \& Edgerton, 1975).

Another difference between the fibre types concerns the activating motor neurons. All fibres within a motor unit are homogeneous regarding their physiological and metabolic properties even if they present a quantitative spectrum for any given variable. The motor nerves for the different fibre types have different thresholds for activation.

The difference is at least partly due to the motor neuron size, the smallest neurons having the lowest threshold. This is called the 'size principle'. The small motor neurons innervate type I fibres, and successively larger motor neurons innervate type IIA and the largest motor neurons innervate type IIB.

This means that the level of excitation will determine which pool of neurons is activated and, thus, which fibre type will contract. The remainder of the neurons are facilitated but fail to reach threshold and discharge. At a low level of motor neuron excitation, some type I fibres will be activated. With increasing excitation, more fibres are activated and with gradually increasing fractions of type IIA and with near-maximal activation, type IIB will also be activated. This increases the muscle tension by varying the number of motor units activated. Another mechanism for increasing tension is to 


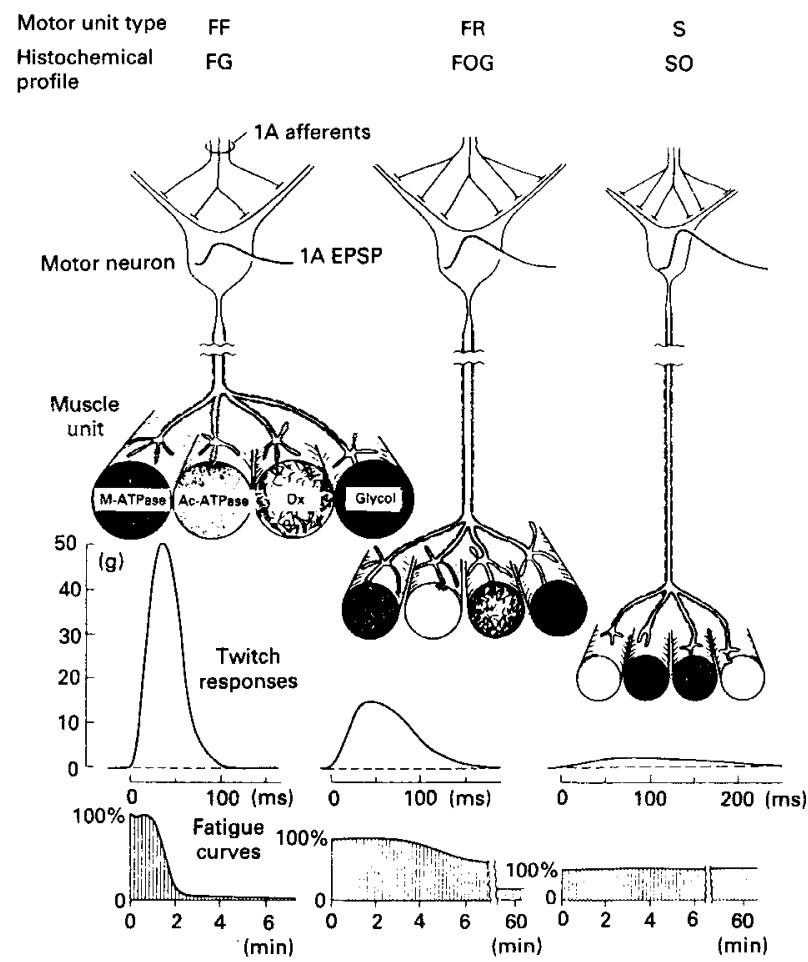

Fig. 1. Diagram summarizing some important features of the organization of motor units in the medial gastrocnemius muscle of the cat. The diameters of muscle fibres and the unit mechanical responses are scaled appropriately for the respective unit groups, representing typical observations. Shading in the muscle fibre outlines denotes relative staining intensities found for each histochemical reaction (M-ATPase, myosin ATPase (EC 3.6.1.33); Ac-ATPase, actomycin ATPase; ox, oxidative enzymes; glycol, glycolytic enzymes). Note differences in pattern as well as intensity of staining in the oxidative enzyme reaction. Note also the somewhat smaller size of motor neuron innervating the type S unit. FF, fast-twitch, fatiguable; FR, fast-twitch, fatigue resistant; S, slow-twitch; FG, fast-twitch, glycolytic; FOG, fast-twitch, oxidative-glycolytic; SO, slow-twitch, oxidative. These two systems are essentially interchangeable (Burke \& Edgerton, 1975).

raise the discharge frequency in the motor nerves. The two phenomena are referred to as 'spatial recruitment' and rate-coding (Monster \& Chan, 1977).

These mechanisms will affect the fuel selection of the muscle during exercise at different intensities, due to the difference in the metabolic architecture of the fibre types.

\section{FUEL SELECTION DURING EXERCISE AT DIFFERENT INTENSITIES}

The three main substrates available for ATP resynthesis during muscle contraction are phosphocreatine (PCr), carbohydrate in the form of muscle glycogen and blood glucose and fat in the form of triacylglycerol, non-esterified fatty acids (NEFA) and ketone bodies. Protein is used to a minor extent and will not be discussed further.

\section{High-intensity exercise}

Intense exercise results in a marked acceleration of the ATP degradation processes including increases in the activities of myosin, $\mathrm{Ca}^{2+}$ and $\mathrm{Na}^{+}-\mathrm{K}^{+}$ATPases (EC 3.6.1.38 
and 3.6.1.37 respectively). A continuation of exercise at the required intensity necessitates a corresponding increase in processes which rephosphorylate the ADP formed. At the beginning of exercise, $\mathrm{O}_{2}$ availability is low and energy will always be mainly provided by anaerobic metabolism. However, at exercise intensities close to the maximum, the aerobic processes will never provide more than $5-10 \%$ of the energy necessary for contraction.

The muscle-biopsy technique, introduced by Jonas Bergström (1962), made it possible to investigate the metabolic changes occurring in skeletal muscle during exercise. It was shown that $6.6 \mathrm{~s}$ of isometric contraction reduced the PCr content in the muscle by $20 \%$ and increased the lactate content by $15 \mathrm{mmol} / \mathrm{kg}$ dry muscle (Bergström et al. 1971). In a series of studies, the same technique was employed, confirming the previous findings (Boobis et al. 1983; Jones et al. 1985) and showing a high lactate accumulation during the first 6.6-10 s of dynamic exercise.

Muscle contraction can also be induced by electrical stimulation. This obviates differences in activation between fibre types and the contraction can be induced at predetermined time intervals and predetermined stimulation frequencies. It is also possible to choose between intact or occluded blood flow to the muscle. With occluded blood flow, the transport to and from the muscle compartment is inhibited. A near-maximum contraction intensity is achieved with a stimulation frequency of $50 \mathrm{~Hz}$.

Muscle sampling and analyses of tissue content showed that even $1.28 \mathrm{~s}$ of stimulation was sufficient to reduce the $\mathrm{PCr}$ content by $11 \mathrm{mmol} / \mathrm{kg}$ dry muscle and increase the lactate by $2 \mathrm{mmol}$. When the contraction time was increased to $2.56 \mathrm{~s}$, the $\mathrm{PCr}$ concentration fell further and the lactate level increased to $8.5 \mathrm{mmol} / \mathrm{kg}$ dry muscle (Hultman \& Sjöholm, 1983). In these studies, muscle samples containing both fibre types were analysed.

In another series of studies, the two fibre types in the biopsy sample were separated and the $\mathrm{PCr}$ and glycogen content were analysed in single fibres or in groups of fibres after characterization (Greenhaff et al. 1991, 1992; Hultman et al. 1991; Söderlund et al. 1992). The electrical stimulation employed was intermittent, with a $1.6 \mathrm{~s}$ contraction and a $1.6 \mathrm{~s}$ rest period. The stimulation frequency was $50 \mathrm{~Hz}$. Biopsy samples were obtained before the stimulation and after 10 and $20 \mathrm{~s}$ of contraction. The two fibre types were separated in the sample and the PCr and glycogen contents were analysed in each fibre type (Hultman et al. 1991). During the first $10 \mathrm{~s}$ of stimulation, the rate of $\mathrm{PCr}$ degradation in the type II fibres averaged $5.3 \mathrm{mmol} / \mathrm{s}$ per $\mathrm{kg}$ dry muscle. The corresponding rate in the type I fibres was $3.3 \mathrm{mmol} / \mathrm{s}$. During the period of $10-20 \mathrm{~s}$ of stimulation, the $\mathrm{PCr}$ degradation rates decreased in type II fibres to $2.1 \mathrm{mmol} / \mathrm{s}$ and in type I fibres to $2.8 \mathrm{mmol} / \mathrm{s}$ per kg dry muscle. At the end of the period, the $\mathrm{PCr}$ content in type II fibres was nearly totally depleted. The glycogen content in the two fibre types was determined and the glycogenolytic rates were also calculated. The glycogenolytic rate was very high $(6.3 \mathrm{mmol} / \mathrm{s}$ per $\mathrm{kg}$ dry muscle) in type II fibres but negligible $(0.6$ $\mathrm{mmol} / \mathrm{s}$ per $\mathrm{kg}$ dry muscle) in type I fibres (Fig. 2).

Similar results are reported in human muscle after repeated bouts of short-term dynamic maximal exercise (Fridén et al, 1989). To study further the glycogenolytic mechanism in the two types of fibre, a series of three experiments was performed. The stimulation protocol was the same, with intermittent stimulation at $50 \mathrm{~Hz}$, and a total stimulation time of $30 \mathrm{~s}$. In five subjects both legs were stimulated, one during adrenaline infusion $(0 \cdot 14 \mu \mathrm{g}$ adrenaline/min per $\mathrm{kg}$ body weight $)$ and the other without infusion. In 
(a)

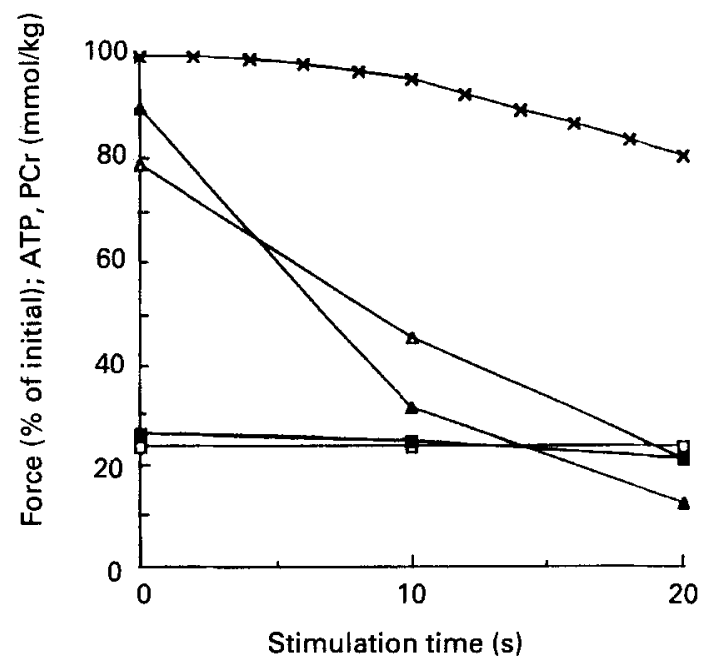

(b)

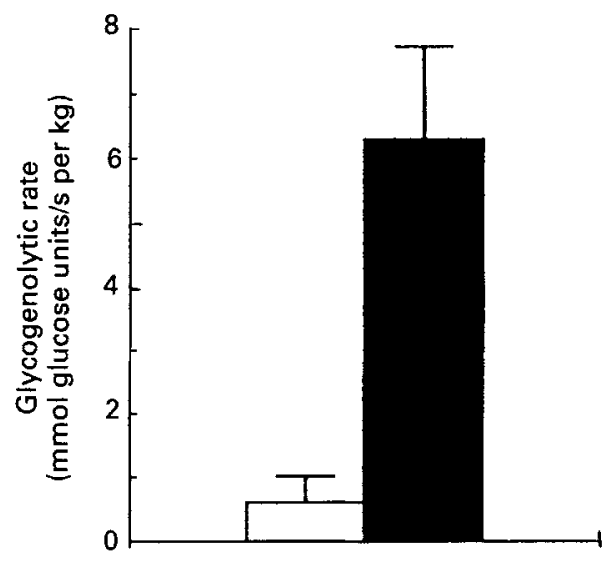

Fig. 2. (a) Whole-muscle force (x) and single-fibre phosphocreatine (PCr; $\triangle, \Delta$ ) and ATP ( $\square$, $\mathbf{0}$ ) concentrations at rest and after 10 and $20 \mathrm{~s}$ of intermittent electrical stimulation at $50 \mathrm{~Hz} .(\triangle, \square)$, type I fibres; $(\boldsymbol{\Lambda}, \boldsymbol{\Xi})$, type II fibres. (b) Glycogenolytic rates in type I and type II fibres during the $20 \mathrm{~s}$ stimulation period. ( $\square$ ), Type I fibres; (ם), type II fibres. Values are means with standard deviations represented by vertical bars.

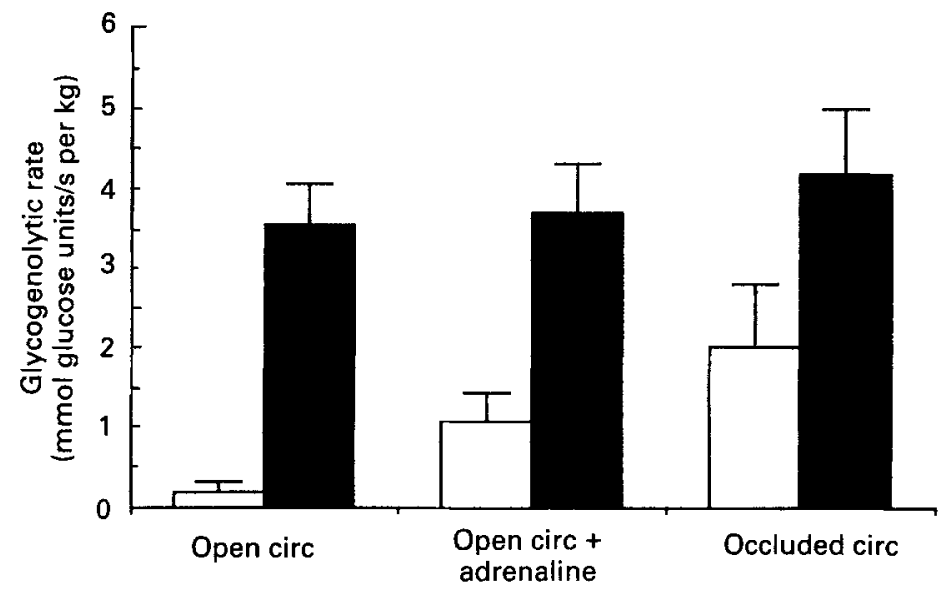

Fig. 3. Glycogenolytic rates in type I ( $\square$ ) and type II ( $\square$ ) fibres during 30 s of intermittent electrical stimulation at $50 \mathrm{~Hz}$. Two experiments were performed, one without and one with adrenaline infusion in the same subjects and the other with circulation (circ) occluded in a separate group of subjects. Values are means with standard deviations represented by vertical bars.

another study, the blood flow to the leg was occluded $30 \mathrm{~s}$ before the start of stimulation and during stimulation. The glycogenolytic rate in type II fibres was unchanged when adrenaline was given and increased only marginally when the blood flow was occluded (see Fig. 3). This was taken to mean that the $50 \mathrm{~Hz}$ stimulation already activated the glycogenolytic pathway in type II fibres maximally when the circulation was still intact, 
and a further increase induced by adrenaline stimulation or anoxia was not possible. The observed rate of glycogenolysis was close to the $V_{\max }$ of the phosphorylase enzyme (glycogen phosphorylase; EC 2.4.1.1) in this fibre type (Harris et al. 1976).

In type I fibres, on the other hand, both the adrenaline infusion and anoxia increased the glycogenolytic rate (Fig. 3). The maximal rate observed in the anoxic muscle in this fibre type is also close to the $V_{\max }$ of phosphorylase, being $50 \%$ lower than that in type II fibres (Harris et al. 1976).

Regulation via glycogen phosphorylase. The difference in glycogenolysis in the two fibre types can be related to the glycogen phosphorylase system. The phosphorylase enzyme is transformed from the inactive phosphorylase $b$ form to the active phosphorylase a form via $\mathrm{Ca}^{2+}$-activated phosphorylation during contraction and/or by a c-AMP increase induced by adrenaline stimulation. However, the activity of phosphorylase a and, consequently the rate of glycogenolysis, also depends on the availability of inorganic phosphate and AMP. AMP functions as an allosteric activator of phosphorylase a (Lowry et al. 1964; Chasiotis, 1983; Ren \& Hultman, 1990) and the formation of AMP during contraction depends on the rate of ADP formation from ATP in relation to the rate of rephosphorylation.

In type II fibres with a high ATPase activity and a high rate of $\mathrm{PCr}$ degradation the phosphorylase system is apparently fully activated in contracting muscle even with an uninhibited $\mathrm{O}_{2}$ supply. On the other hand, in type I fibres, with a low ATPase activity and a high oxidative capacity, full activation of phosphorylase is reached first after inhibition of the oxidative rephosphorylation of ADP resulting in an increase in AMP.

These results of maximum stimulation of the mixed muscle show the difference between the fibres: a higher rate of energy release in type II fibres compensated by a higher degradation rate of $\mathrm{PCr}$ and a higher glycogenolytic rate, despite an equal stimulation of both types of fibre. At the same time, the oxidative energy release was higher in type I fibres.

\section{Exercise of low-to-moderate intensity}

Fibre recruitment. During exercise of low-to-moderate intensity, most of the energy is derived from the oxidative phosphorylation of carbohydrate and fat. As mentioned previously, the activation threshold is low in type I motor neurons and it increases in neurons activating type IIA to type IIB. This means that at a low exercise intensity, the type I fibres with a high oxidative capacity will do most of the contractile work, while increasing numbers of type IIA and B fibres will take part in energy production when the work intensity increases.

In a recent study by Ball-Burnett et al. (1990), a 2 h period of dynamic exercise was performed at an intensity of $61 \% V_{\mathrm{O}_{2} \max }$. The glycogen degradation, as estimated in pooled samples of fibres, was most pronounced in type I fibres. Histochemical analyses showed that the glycogen loss during the first $15 \mathrm{~min}$ of exercise was detectable in $75 \%$ of type I fibres, compared with $28 \%$ of type II fibres. These results confirm earlier studies with histochemical analyses of glycogen degradation during exercise which show that glycogen depletion initially occurs in type I fibres, and then gradually increases, first in type IIA fibres and then in type IIB fibres (Gollnick et al. 1973; Essén, 1978; Thomson et al. 1979; Völlestad \& Blom, 1985).

Measurements in pools of type I and type II fibres showed that the lactate concen- 
trations were higher in type II pools from muscle samples obtained after 15 and 60 min. This is surprising since only a small fraction of the fibres in these pools was activated and the mean glycogen degradation was much lower than that in type I fibres. The results, however, accord with the differences between fibres, i.e. a lower activation threshold combined with a higher oxidative capacity in type I fibres, as compared with a higher activation threshold, and higher glycolytic and lower oxidative capacities in type II fibres.

Fuel for oxidative metabolism. The two main fuels for oxidative metabolism in muscle are fat and carbohydrate. The maximum rates of ATP production from the two fuels differ, being about $100 \%$ higher for carbohydrate oxidation than for fat, i.e. $2.7 \mathrm{mmol}$ ATP/s per kg dry muscle for carbohydrate (Jorfelt \& Wahren, 1971) v. 1.4 mmol ATP/s per kg dry muscle for the maximum rate of fat combustion (Davies \& Thompson, 1979). Another difference between the fuels is the time needed to reach the maximal ATP production rate, which is approximately $3 \mathrm{~min}$ for carbohydrate and approximately 30 min for fat (Sahlin, 1986). The delay in maximal power production by fat is due to the fact that the main oxidative substrate consists of non-esterified fatty acids (NEFA) released from triacylglycerol (TAG) stores in adipose tissue and muscle. The release is regulated by the sympathetic nervous system (Havel \& Goldfein, 1959), with a gradual increase in epinephrine release during continuous exercise. At the same time, the plasma level of insulin decreases (Galbo et al. 1977). An increase in the concentration ratio epinephrine:insulin will release NEFA from the TAG stores with an elevation of the plasma NEFA concentration up to ten times when the exercise is prolonged. A close relationship has been observed between the plasma NEFA concentration and the amount of NEFA being oxidized (Hagenfeldt \& Wahren, 1971).

In resting muscle, values for the respiratory exchange ratio of individuals consuming an average mixed diet are $0.80-0.85$, which indicates that the contribution of fat to oxidative metabolism is about $50 \%$, corresponding to $4.5 \mathrm{~g}$ fat oxidized/h (Gollnick \& Saltin, 1988). At the start of exercise both fuels are utilized. When the intensity of the exercise increases both fuels are increasingly utilized with a peak value for fat utilization at an intensity of about $50 \% V_{\mathrm{O}_{2} \max }$. Thereafter, the combustion of fat decreases in absolute and in relative terms. The turning point in fat utilization denotes the maximal power for NEFA oxidation and, consequently, the maximal exercise intensity for which all the required ATP can be produced by the oxidation of NEFA.

The reason for the decrease in fat utilization at higher exercise intensities is not clear. It has been suggested that increases in the level of lactate in blood may retard NEFA release (Fredholm, 1969; Boyd et al. 1974; Issekutz et al. 1975) and, thus, reduce the availability of NEFA in parallel with increasing work intensity. Some findings also indicate that the degree of fat utilization can be regulated by the availability of $\mathrm{O}_{2}$. The ATP yield per mol $\mathrm{O}_{2}$ is lower when NEFA are oxidized $(5.65)$ than when glycogen is oxidized $(6 \cdot 0)$. When the $\mathrm{O}_{2}$ tension in muscle becomes limiting muscle glycogen becomes the preferred fuel. Studies by Linnarsson (1974) showed a negative relationship between $\mathrm{RQ}$ and the $\mathrm{O}_{2}$ content of the inhaled air during exercise. However, other regulatory mechanisms in the muscle fibres cannot be excluded.

The NEFA in muscle cells are activated by $\mathrm{CoASH}$, transferred into mitochondria via a carnitine-dependent shuttle mechanism and subsequently oxidized to acetyl-CoA, i.e. the same product that is produced from carbohydrate degradation by pyruvate dehydrogenase complex $(\mathrm{PDH})$. The acetyl-CoA formation in muscle mitochondria is, thus, dependent on both the lipolytic and the glycolytic pathways and the concentration of 
acetyl-CoA is a potential regulator of both $\beta$-oxidation and of the activity of pyruvate oxidation by PDH.

Regulation of the pyruvate dehydrogenase complex. The PDH is a multi-enzyme complex which catalyses the irreversible oxidative decarboxylation of pyruvate to acetyl-CoA and regulates the entry of carbohydrate into the tricarboxylic acid cycle. Closely associated with the complex are the regulatory enzymes PDH phosphatase (EC 3.1.3.43) and PDH kinase (EC 2.7.1.99) which regulate the phosphorylation state and determine the extent of PDH transformation to its active form, PDHa. The phosphorylated form is inactive while dephosphorylation reactivates the enzyme. Thus, the concerted action of the kinase and the phosphatase determines the PDHa fraction and, therefore, the pathway substrate flux into the citric acid cycle from carbohydrate sources. PDH phosphatase is activated by $\mathrm{Ca}^{2+}, \mathrm{Mg}^{2+}$ and $\mathrm{NAD}^{+}$, and inhibited by NADH. Conversely, PDH kinase is activated by NADH, acetyl-CoA, an increasing concentration ratio acetyl-CoA:CoASH and inhibited by pyruvate, $\mathrm{NAD}^{+}, \mathrm{CoASH}$ and ADP. The main physiological activators of the transformation to PDHa and of the catalytic activity are intramitochondrial concentrations of pyruvate and $\mathrm{Ca}^{2+}$, while inhibitors are the concentration ratios acetyl-CoA:CoASH and NADH:NAD ${ }^{+}$. Most studies of PDH regulation are performed in resting muscle in vitro or in skeletal muscle or heart in situ without definition of contractile activity (for recent reviews, see Roche \& Patel, 1989; Behal et al. 1992).

Metabolic regulation in contracting muscle. The initiation of muscle contraction by $\mathrm{Ca}^{2+}$ release from the sarcoplasmic reticulum activates actomyosin ATPase with the formation of ADP and AMP. At the same time, glycogenolysis is activated by $\mathrm{Ca}^{2+}$-induced transformation of glycogen phosphorylase to the active form. Similarly, an increase in $\mathrm{Ca}^{2+}$ transforms PDH to the active form and also activates $\alpha$-ketoglutarate dehydrogenase (EC 1.2.4.2; Fig. 4).

The catalytic activity of the glycolytic pathway is enchanced by $\mathrm{PCr}$ degradation with phosphate release and by the formation of ADP and AMP. The formation of pyruvate further activates PDHa and, if NAD and CoASH are available, acetyl-CoA is formed. The acetyl-CoA is condensed with oxaloacetate to citrate and is further utilized in the tricarboxylic acid cycle with the formation of $\mathrm{NADH}$ and $\mathrm{CO}_{2}$. The critical point for continuation of the $\mathrm{PDH}$ reaction is the condensation of acetyl-CoA in the citric acid cycle with the release of $\mathrm{CoASH}$ and the oxidation of $\mathrm{NADH}$ to NAD ${ }^{+}$in the electron transport chain. The maximum rate of acetyl-CoA formation in the $\mathrm{PDH}$ reaction is in the order of 2-3 mmol acetyl-CoA/min per $\mathrm{kg}$ wet muscle, while the total CoASH store is about $15-20 \mu \mathrm{mol} / \mathrm{kg}$ wet muscle. The whole store of $\mathrm{CoASH}$, thus, can be acetylated and the PDH activity inhibited in $1 \mathrm{~s}$. There exists, however, a buffering mechanism, the carnitine acetyltransferase ( $E C$ 2.3.1.7) system, by which acetyl groups from acetyl-CoA are transferred to carnitine. Carnitine and acetylcarnitine pass through the mitochondrial membrane via a specific translocase and, thus, are distributed throughout the whole cell. The total carnitine content in the cell is $5-6 \mathrm{mmol} / \mathrm{kg}$ wet muscle. The acetyl groups entering the cytoplasm as acetylcarnitine will equilibrate with the small extramitochondrial $\mathrm{CoASH}$ pool (about $5 \%$ of the whole pool) which becomes partly acetylated and the concentration of free CoASH in the sarcoplasm decreases (Fig. 4).

The formation of fatty-acyl-CoA esters from long-chain NEFA is dependent on the activity of acyl-CoA synthetases, the activity of which is regulated by the concentration ratio acyl-CoA:CoASH and the concentration of $\mathrm{CoASH}$ extramitochondrially. The 


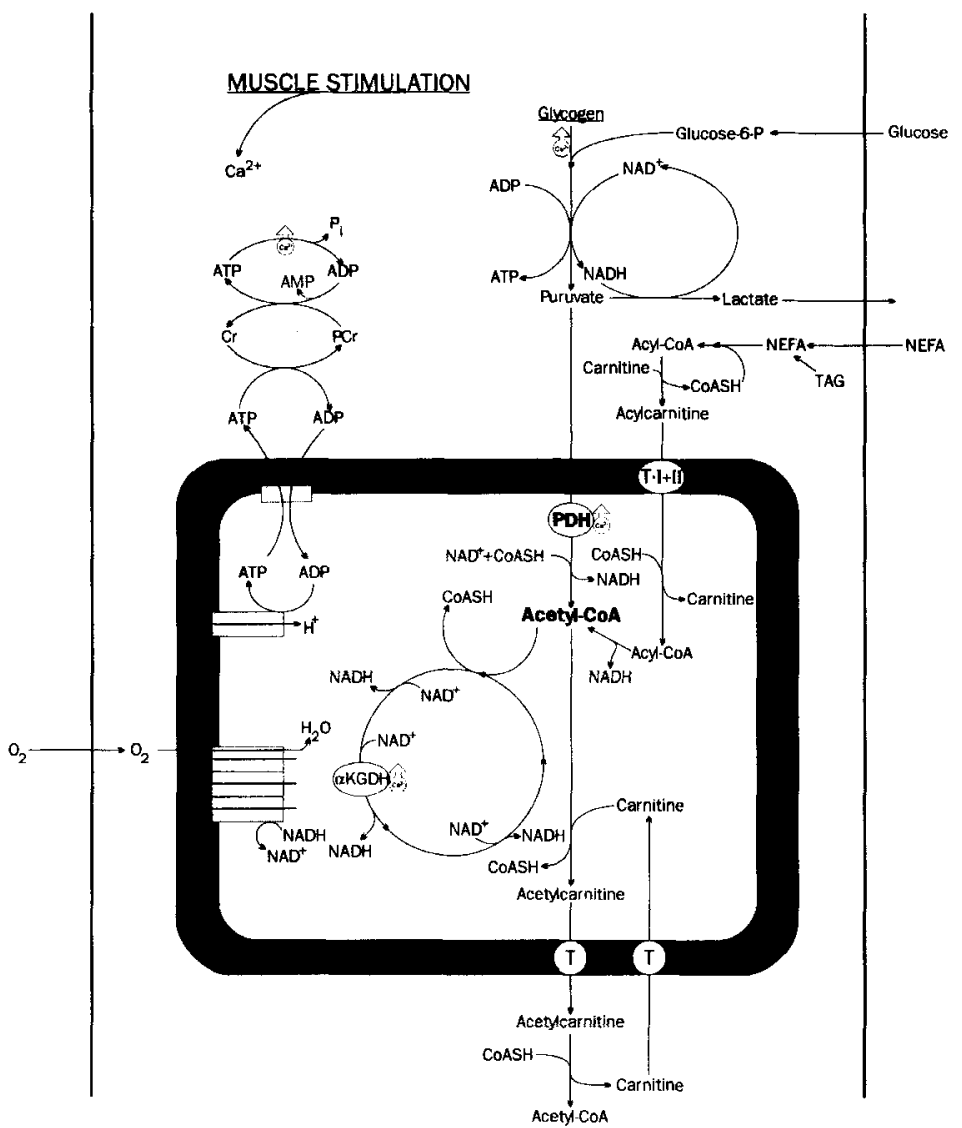

Fig. 4. Metabolic processes in contracting muscle. Cr, creatine; PCR, phosphocreatine; $\alpha-\mathrm{KGDH}$, $\alpha$-ketoglutarate dehydrogenase (EC 1.2.4.2); NEFA, non-esterified fatty acids; TAG, triacylglycerols; PDH, pyruvate dehydrogenase complex.

intramitochondrial CoASH concentration is also important for the activity of carnitinepalmitoyl transferase II (EC 2.3.1.21) and, thus, for the transport of fatty acyl groups into the mitochondrion (Newsholme \& Leech, 1988). The concentration ratio acetyl-CoA:CoASH in the mitochondrion, which is a potential regulator of PDH activity, may also regulate the availability of fatty acyl groups for $\beta$-oxidation in the mitochondrion.

Pyruvate dehydrogenase activity and acetyl group accumulation during exercise. The degree of PDH transformation is dependent on exercise intensity, as shown in a study by Constantin-Teodosiu et al. (1991). Short-term exercise was performed at intensities of 30,60 , and $90 \% V_{\mathrm{O}_{2} \text { max }}$. The PDHa activity increased from $0.4 \mathrm{mmol}$ acetyl-CoA $/ \mathrm{min}$ per kg wet muscle at rest to 0.8 at $30 \% V_{\mathrm{O}_{2} \max }$ and to 1.2 at 60 and $90 \% V_{\mathrm{O}_{2} \text { max }}$. At the same time, the acetyl-CoA:CoASH ratio increased from 0.34 at rest to $0.37,0.65$ and 1.03 during the incremental exercise. The acetylcarnitine:carnitine ratio showed a similar increase from 0.39 in resting muscle to $0.48,0.94$ and 2.34 during the exercise. During the exercise, the PDH transformation to the active form increased, despite the increasing concentration ratio, acetyl-CoA:CoASH. This is probably caused by the $\mathrm{Ca}^{2+}$ 
stimulation of PDH phosphatase which overrides the inhibition by the increase in acetyl-CoA:CoASH. Similar results were obtained in other exercise studies (ConstantinTeodosiu et al. 1992; Putman et al. 1993).

There was also an increase in the lactate concentration in muscle together with the accumulation of acetyl groups at exercise intensities of 60 and $90 \% V_{\mathrm{O}_{2} \max }$, indicating a rate of pyruvate formation higher than the catalytic activity of PDH. At the same time, the rate of acetyl group formation is apparently higher than the condensation with oxaloacetate in the tricarboxylic acid cycle. The increase in the concentration ratio acetyl-CoA:CoASH during the intense exercise may, as discussed previously, inhibit fatty-acyl-CoA formation and mitochondrial uptake because of a decreased availability of CoASH and carnitine and, thus, inhibit the oxidative utilization of NEFA. This mechanism could explain both the decreased utilization of fat when the exercise intensity increases and the reliance on carbohydrate as fuel at intensities above $70 \% \quad V_{\mathrm{O}_{2} \max }$ (Christensen \& Hansen, 1939; Bergström et al. 1967).

\section{GLUCOSE-FATTY ACID CYCLE}

In classical studies by Randle and coworkers in the early 1960s (Garland et al. 1963, 1964; Garland \& Randle, 1964) it was observed experimentally that the presence of an alternative substrate, such as fatty acid or ketone bodies, suppressed the utilization of carbohydrate by heart tissue (Garland et al. 1963, 1964), and that this could be related to the acetyl-CoA inhibition of PDH (Garland \& Randle, 1964). It has also been shown that prolonged starvation results in a partial or complete inactivation of $\mathrm{PDH}$ in all tissues, except the central nervous system (Wieland, 1983; Randle, 1986; Sugden \& Holness, 1989). The mechanism suggested for the so-called glucose-fatty acid cycle is an inhibition of PDH caused by an increase in acetyl-CoA, but also an inhibition of glycolysis by a suppression of phosphofructokinase $(E C 2.7 .1 .11$; PFK) activity resulting from an increase in the accumulation of citrate when lipid substrate is oxidized (Garland et al. 1963, 1964). Issad et al. (1987) concluded that prolonged starvation restricts glucose uptake and its utilization by the preferential oxidation of lipid fuels, particularly by working muscle with initially high rates of glucose utilization, including the heart. An increased concentration of NEFA in plasma has been shown to have a sparing effect on muscle and liver glycogen contents in the exercising rat (Rennie et al. 1976).

Putman et al. (1993) analysed muscle metabolism during exercise performed after two diets, one with a low carbohydrate content (LCD) and the other with a high carbohydrate content (HCD). The diets, followed for $3 \mathrm{~d}$ after a glycogen-depleting exercise, resulted in a low muscle glycogen content and high plasma lipids after LCD and high muscle glycogen content and normal plasma lipids after HCD. The first exercise was done after LCD and continued until exhaustion. About 3 weeks later the exercise was repeated after $3 \mathrm{~d}$ of $\mathrm{HCD}$. The exercise intensities $\left(75 \% V_{\mathrm{O}_{2} \max }\right)$ and durations were equal in the two series. Muscle samples taken at rest showed, as expected, high concentrations of acetyl-CoA and acetylcarnitine, a low PDHa fraction and an increase in citrate after the LCD, as compared with those for the muscle sample obtained after HCD. During exercise, the PDHa fraction increased with both diets but to a lower maximal level after LCD as compared with HCD, where $100 \%$ of the PDH was dephosphorylated to PDHa. The acetyl group accumulation, however, showed completely different patterns, decreasing rapidly after $L C D$ and increasing to high concen- 


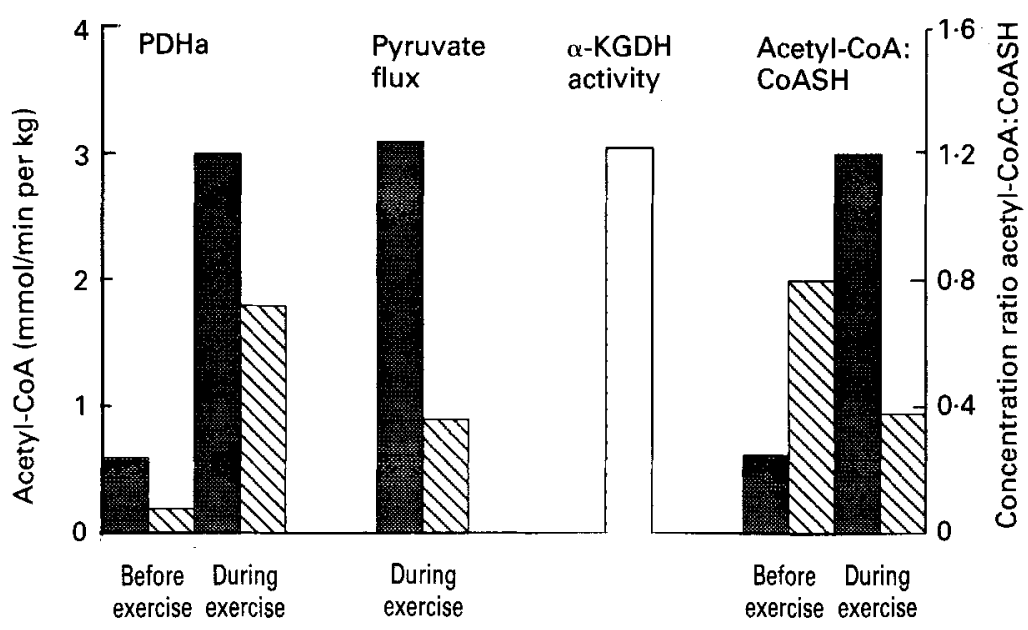

Fig. 5. Pyruvate dehydrogenase (EC 1.2.4.1; $\mathrm{PDH}$ ) activity and regulation during two exercise periods after different diets. The first exercise was performed after a $3 \mathrm{~d}$ period on a diet with low carbohydrate content $(\mathrm{LCD} ; \mathrm{N})$ and the second exercise after $3 \mathrm{~d}$ on a diet with high carbohydrate content (HCD; $\mathbf{m}$ ). The activity of $\alpha$-ketoglutarate dehydrogenase (EC 1.2.4.2; $\alpha-\mathrm{KGDH})$ is from Blomstrand et al. (1986). PDHa activity in muscle samples obtained before and at the end of the exercise periods is determined in vitro. The pyruvate flux through $\mathrm{PDH}$ is calculated from glycogen degradation and glucose uptake with deduction of pyruvate used for formation of lactate and anaplerotic substrates during the exercise period from 16 min to end of exercise (approximately $47 \mathrm{~min}$ ). The activity of $\alpha-\mathrm{KGDH}$ is a measure of the maximum flux through the cycle. Values for the concentration ratio acetyl-CoA:CoASH were measured in muscle samples obtained before and at the end of the exercise periods.

trations after $\mathrm{HCD}$. The citrate content in muscle increased in both experiments, but the difference between the diets was eliminated. The flux through the PDH enzyme during exercise after LCD was calculated as $0.9 \mathrm{mmol}$ pyruvate $/ \mathrm{min}$ per $\mathrm{kg}$ wet muscle, corresponding to $50 \%$ of the PDHa activity measured in vitro $(1.88 \mathrm{mmol} / \mathrm{min}$ per $\mathrm{kg})$, while after $\mathrm{HCD}$ the flux was $3.1 \mathrm{mmol} / \mathrm{min}$ per $\mathrm{kg}$ wet muscle, corresponding to $100 \%$ of the activity of PDHa (Fig. 5).

The maximum flux of acetyl groups in the tricarboxylic acid cycle has been estimated by Blomstrand et al. (1986) as the activity of $\alpha$-ketoglutarate dehydrogenase enzyme in the quadriceps femoris muscle of well-trained athletes. The activity was $3 \cdot 1$ (SD $0 \cdot 26)$ $\mathrm{mmol} / \mathrm{min}$ per $\mathrm{kg}$, thus closely corresponding to the catalytic activity of PDH during exercise after the high-carbohydrate diet. It was concluded that the oxidative energy release was completely covered by pyruvate oxidation by $\mathrm{PDH}$, excluding the utilization of fat in the quadriceps muscle during the exercise after HCD.

After LCD, on the other hand, the PDH activity represented only about $30 \%$ of the oxidative metabolism, while about $70 \%$ was derived from fat metabolism. Substrate differences after the two diets were a high availability of fat and low glycogen in muscle after LCD and a high muscle glycogen content after HCD. The concentration ratio acetyl-CoA:CoASH at the end of exercise was 0.4 after LCD v. 1.2 after HCD, and the free carnitine concentration was $9 v .3 \mathrm{mmol} / \mathrm{kg}$ dry muscle respectively. Those differences, as discussed previously, might activate the utilization of lipids after LCD and inhibit the metabolism of fat after HCD. 


\section{ROLE OF SUBSTRATE AVAILABILITY}

In a recent study by Dyck et al. (1993), a fat emulsion and heparin were infused before and during a 15 min period of exercise and the substrate utilization was compared with a similar period of exercise without the infusion. The work intensity was $85 \% V_{\mathrm{O}_{2} \max }$. The glycogen utilization was reduced by $40 \%$ when fat was infused, but in both series the PDHa fraction was high and the accumulations of acetyl-CoA and acetylcarnitine were similar with and without the fat infusion. The amounts of lactate formed were also equal in both exercise series.

The availability of large amounts of fat can seemingly increase the utilization of fat and spare glycogen despite the accumulation of acetyl groups and without the inhibition of $\mathrm{PDH}$ transformation. In this experiment, also, the citrate concentration increased in the resting muscle after the fat infusion, which indicates that the mitochondrial uptake and utilization of fat had occurred before the exercise was started. Pre-formed fatty-acylCoA and fatty-acyl carnitine could then be utilized during the short-lasting exercise in parallel with the pyruvate formed from glycolysis. Apparently the increased availability of fat inhibited both the glycogenolytic activity, and the flux through PDH, possibly primarily in type I fibres, while type II fibres still produced lactate at unchanged rate. The results are not in accordance with the classical glucose-fatty acid cycle.

\section{SUMMARY}

The fuel selection of muscle fibres at rest is dependent on substrate availability. Increased lipid availability results in an increased citrate concentration with inhibition of glycolysis. Fat utilization also increases the concentration ratio acetyl-CoA:CoASH, with inhibition of PDH transformation to the active form. The result is an inhibition of carbohydrate utilization in conformity with the classical glucose-fatty acid cycle.

During exercise fuel selection is dependent on the intensity of exercise, the recruitment pattern of fibre type and the availability of fuels. During exercise at maximum intensity the main fuels are $\mathrm{PCr}$ and muscle glycogen, the highest energy release occurring with type II fibres.

At exercise intensities between 70 and $100 \% V_{\mathrm{O}_{2} \max }$ carbohydrate is the main fuel after the intake of normal mixed or carbohydrate-rich diets. No inhibition of PDHa formation was observed by increased concentration ratio acetyl-CoA:CoASH during the exercise, but the activation and transport of fatty-acyl groups from NEFA may be inhibited by a decrease in the concentration of CoASH. This mechanism may limit the contribution of fat to metabolism during exercise at intensities above $60 \% \quad V_{\mathrm{O}_{2} \max }$, after an intake of carbohydrate-rich diets.

After carbohydrate starvation or an infusion of a fat emulsion, there was a substantial increase in the utilization of fat which, after the infusion, was concomitant with a high PDHa and a high lactate production. This is thought to be due to a decrease in glycolysis and in the catalytic activity of PDHa, especially in type I fibres, while lactate production continues in type II fibres.

When exercise intensities fall below $60 \% V_{\mathrm{O}_{2} \max }$, fat becomes the dominant fuel during prolonged exercise. At the same time the recruitment pattern is shifted toward type I fibres which have the lowest activation threshold and the highest oxidative capacity. 


\section{REFERENCES}

Armstrong, R. B. (1988). Muscle fibre recruitment patterns and their metabolic correlates. In Exercise, Nutrition and Energy Metabolism, pp. 9-26 [E. S. Horton and R. L. Terjung, editors]. New York: Macmillan Publishing Company.

Ball-Burnett, M., Gren, H. J. \& Houston, M. E. (1990). Energy metabolism in human slow and fast twitch fibres during prolonged cycle exercise. Journal of Physiology 437, 257-267.

Behal, R. H., Buxton, D. B., Robertson, J. G. \& Olson, M. S. (1993). Regulation of the pyruvate dehydrogenase multienzyme complex. Annual Review of Nutrition 13, 497-520.

Bergström, J. (1962). Muscle electrolytes in man. Determined by neutron activation analysis on needle biopsy specimens. A study on normal subjects, kidney patients, and patients with chronic diarrhoea. Scandinavian Journal of Clinical and Laboratory Investigation 14, Suppl., 68.

Bergström, J., Harris, R. C., Hultman, E. \& Nordesjö, L.-O. (editors) (1971). Energy rich phosphogens a dynamic and static work. Advances in Experimental Medicine and Biology, vol. II, Muscle Metabolism During Exercise, pp. 341-355. New York: Plenum Press.

Blomstrand, E., Ekblom, B. \& Newsholme, E. A. (1986). Maximum activities of key glycolytic and oxidative enzymes in human muscle from differently trained individuals. Journal of Physiology 381, 111-118.

Boobis, L. H., Williams, C. \& Wootton, S. A. (1983). Human muscle metabolism during brief maximal exercise. Journal of Physiology 338, 21P-22P.

Boyd, A. E., Giamber, S. R., Mager, M. \& Lebovietz, H. E. (1974). Lactate inhibition of lipolysis in exercising man. Metabolism 23, 531-542.

Burke, R. E. \& Edgerton, V. R. (1975). Motor unit properties and selective involvement in measurements. Exercise and Sport Sciences Reviews 3, 31-81.

Chasiotis, D. (1983). The regulation of glycogen phosphorylase and glycogen breakdown in human skeletal muscle. Acta Physiologica Scandinavica, Suppl. 518, 68.

Christensen, E. H. \& Hansen, O. (1939). Arbeitsfähigkeit und Ernährung (Ability to work and nutrition). Scandinavian Archives of Physiology 81, 160-171.

Constantin-Teodosiu, D., Carlin, J. I., Cederblad, G., Harris, R. C. \& Hultman, E. (1991). Acetyl group accumulation and pyruvate dehydrogenase activity in human muscle during incremental exercise. Acta Physiologica Scandinavica 143, 367-372.

Constantin-Teodosiu, D., Cederblad, G. \& Hultman, E. (1992). PDC activity and acetyl group accumulation in skeletal muscle during prolonged exercise. Journal of Physiology 73, 2403-2407.

Davies, C. T. M. \& Thompson, M. V. (1979). Aerobic performance of female marathon and male ultramarathon athletes. European Journal of Applied Physiology 41, 233-245.

Dyck, D. J., Putman, C. T., Heigenhauser, G. J. F., Hultman, E. \& Spriet, L. L. (1993). Regulation of fat-carbohydrate interaction in skeletal muscle during intense aerobic cycling. American Journal of Physiology 265, 852-859.

Essến, B. (1978). Glycogen depletion of different fibre types in human skeletal muscle during intermittent and continuous exercise. Acta Physiologica Scandinavica 554, Suppl., 36-48.

Fredholm, B. B. (1969). Inhibition of fatty acid release from adipose tissue by high arterial blood concentrations of lactate. Acta Physiologica Scandinavica 77, Suppl., 330.

Fridén, J., Seger, J. \& Ekblom, B. (1989). Topographical localization of muscle glycogen: an ultrahistochemical study in the human vastus lateralis. Acta Physiologica Scandinavica 135, 381-391.

Galbo, H., Christensen, N. J. \& Host, J. J. (1977). Catecholamines and pancreatic hormones during autonomic blockade in exercising man. Acta Physiologica Scandinavica 101, 428.

Garland, P. B., Newsholme, E. A. \& Randle, P. J. (1964). Effects of fatty acids and ketone bodies and of alloxan diabetes and starvation on pyruvate metabolism. Biochemical Journal 93, 665-678.

Garland, P. B. \& Randle, P. J. (1964). Control of pyruvate dehydrogenase in the perfused rat heart by the intracellular concentration of acetyl CoA. Biochemical Journal 91, 6C-7C.

Garland, P. B., Randle, P. J. \& Newsholme, E. A. (1963). Citrate as an intermediary in the inhibition of phosphofructokinase in rat heart muscle by fatty acids, ketone bodies, pyruvate, diabetes and starvation. Nature 200, 169-170.

Gollnick, P. D., Armstrong, R. B., Saubert, C. W. IV, Sembrowich, W. L., Shepherd, R. E. \& Saltin, B. (1973). Glycogen depletion patterns in human skeletal muscle fibres during prolonged work. Pflügers Archiv 344, 1-2. 
Gollnick, P. D. \& Saltin, B. (1988). Fuel for muscular exercise: role of fat. In Exercise, Nutrition and Energy Metabolism, pp. 72-88 [E. S. Horton and R. L. Terjung, editors]. New York: Macmillan Publishing Company

Greenhaff, P. L., Söderlund, K., Ren, J.-M. \& Hultman, E. (1992). Energy metabolism in single human muscle fibres during intermittent contraction with occluded circulation. Journal of Physiology 460, 443-453.

Greenhaff, P. P., Ren, J.-M., Söderlund, K. \& Hultman, E. (1991). Energy metabolism in single human muscle fibers during contraction without and with epinephrine infusion. American Journal of Physiology 260, E713-E718.

Hagenfeldt, L. \& Wahren, J. (1971). Metabolism of free fatty acids and ketone bodies in skeletal muscle. In Muscle Metabolism During Exercise, pp. 153-163 [B. Pernow and B. Saltin, editors]. New York: Plenum Press.

Harris, R. C., Essén, B. \& Hultman, E. (1976). Glycogen phosphorylase activity in biopsy samples and single muscle fibres of musculus quadriceps femoris of man at rest. Scandinavian Journal of Clinical and Laboratory Investigation 36, 521-526.

Havel, R. J. \& Goldfein, A. (1959). The role of the sympathetic nervous system in the metabolism of free fatty acids. Journal of Lipid Research 1, 102-108.

Henriksson, J. (1995). Muscle fuel selection: effect of exercise and training. Proceedings of the Nutrition Society 54, 125-138.

Hultman, E., Greenhaff, P. L., Ren, J.-M. \& Söderlund, K. (1991). Energy metabolism and fatigue during intense muscle contraction. Biochemical Society Transactions 19, 347-353.

Issad, T., Penicaud, L., Ferré, P., Kandé, J., Baudon, M.-A. \& Girard, J. (1987). Effects of fasting on tissue glucose utilisation in conscious resting rats. Major glucose-sparing effect in working muscles. Biochemical Journal 246, 241-244.

Issekutz, B. Jr, Shaw, W. A. \& Issekutz, T. B. (1975). Effect of lactate on the FFA and glycerol turnover in resting and exercising dogs. Journal of Applied Physiology 39, 349-353.

Jones, N. L., McCartney, N., Graham, T., Spriet, L. L., Kowalchuk, J. M., Heigenhauser, G. J. F. \& Sutton, J. R. (1985). Muscle performance and metabolism in maximal isokinetic cycling at slow and fast speeds. Journal of Applied Physiology 59, 132-136.

Jorfeldt, L. \& Wahren, J. (1971). Leg blood flow during exercise in man. Clinical Science 41, 459-473.

Linnarsson, D. (1974). Dynamics of preliminary gas exchange and heart rate changes at start and end of exercise. Acta Physiologica Scandinavica 415, Suppl., 5-68.

Lowry, O. H., Schulz, D. W. \& Passonneau, J. V. (1964). Effects of adenylic acid on the kinetics of muscle phosphorylase a. Journal of Biological Chemistry 239, 1947-1953.

Monster, A. W. \& Chan, H. (1977). Isometric force production by motor units of extensor digitorum communis muscle in man. Journal of Neurophysiology 40, 1432-1443.

Newsholme, E. A. \& Leech, A. R. (1988). The integration of metabolism during starvation, refeeding, and injury. Biochemistry for the Medical Sciences, pp. 330-331. Toronto: Wiley.

Pette, D. \& Staron, R. S. (1990). Cellular and molecular diversities of mammalian skeletal muscle fibers. Reviews of Physiology, Biochemistry and Pharmacology 116, 1-76.

Putman, C. T., Spriet, L. L., Hultman, E., Lindinger, M. I., Lands, L. C., McKelvie, R. S., Cederblad, G., Jones, N. L. \& Heigenhauser, G. J. F. (1993). Pyruvate dehydrogenase activity and acetyl group accumulation during exercise after different diets. American Journal of Physiology 265, E752-E760.

Randle, P. J. (1986). Fuel selection in animals. Biochemical Society Transactions 14, 799-806.

Ren, J.-M. \& Hultman, E. (1990). Regulation of phosphorylase a activity in human skeletal muscle. Journal of Applied Physiology 69, 919-923.

Rennie, M. J., Winder, W. W. \& Holloszy, J. O. (1976). A sparing effect of increased plasma fatty acid on muscle and liver glycogen content in exercising rat. Biochemical Joumal 156, 647-655.

Roche, T. E. \& Patel, M. S. (1989). $\alpha$-Keto acid dehydrogenase complexes: organization, regulation and biomedical ramifications. Annals of the New York Academy of Sciences 573, 1-473.

Sahlin, K. (1986). Metabolic changes limiting muscle performance. In International Series on Sport Sciences, vol. 16, Biochemistry of Exercise VI, pp. 323-342 [B. Saltin, editor]. Champaign, Ill.: Human Kinetics Publishers.

Söderlund, K., Greenhaff, P. L. \& Hultman, E. (1992). Energy metabolism in type I and type II human muscle fibres during short term electrical stimulation at different frequencies. Acta Physiologica Scandinavica 144, $15-22$.

Sugden, M. C. \& Holness, M. J. (1989). Effects of re-feeding after prolonged starvation on pyruvate dehydrogenase activities in heart, diaphragm and selected skeletal muscles of the rat. Biochemical Journal 262, 669-672. 
Thomson, J. A., Green, H. J. \& Houston, M. E. (1979). Muscle glycogen depletion patterns in fast twitch fibre subgroups of man during submaximal and supramaximal exercise. Pflügers Archiv 379, 105-108.

Völlestad, N. K. \& Blom, P. C. S. (1985). Effect of varying exercise intensity on glycogen depletion in human muscle fibres. Acta Physiologica Scandinavica 125, 395-405.

Wieland, O. H. (1983). The mammalian pyruvate dehydrogenase complex: structure and regulation. Reviews of Physiology, Biochemistry and Pharmacology 96, 123-170. 